\title{
Anti-senescence efficacy of radio-electric asymmetric conveyer technology
}

\author{
Margherita Maioli • Salvatore Rinaldi • Sara Santaniello • \\ Alessandro Castagna - Gianfranco Pigliaru - Alessandro Delitala • \\ Matteo Lotti Margotti • Luigi Bagella • Vania Fontani • Carlo Ventura
}

Received: 1 January 2013 / Accepted: 24 April 2013 /Published online: 9 May 2013

(C) The Author(s) 2013. This article is published with open access at Springerlink.com

\begin{abstract}
Recent evidence suggests that ageing-related diseases could result in an accelerated loss of selfrenewal capability of adult stem cells, normally involved in replacing damaged cellular elements. In previous works, we highlighted that a specific treatment, named tissue optimization-regenerative (TO-RGN), of radioelectric asymmetric conveyer (REAC) technology, influenced gene expression profiles controlling stem cell differentiation and pluripotency of human skin-derived
\end{abstract}

M. Maioli $\cdot$ S. Santaniello $\cdot$ G. Pigliaru $\cdot$ A. Delitala $\cdot$

L. Bagella

Department of Biomedical Sciences, University of Sassari,

Viale San Pietro, 43/B, 07100 Sassari, Italy

M. Maioli · S. Santaniello $\cdot$ G. Pigliaru $\cdot$ C. Ventura Laboratory of Molecular Biology and Stem Cell

Engineering, National Institute of Biostructures and

Biosystems, Bologna, Italy

M. Maioli $\cdot$ S. Rinaldi $(\bowtie) \cdot$ A. Castagna $\cdot$ V. Fontani

C. Ventura

Department of Regenerative Medicine, Rinaldi Fontani Institute, Viale Belfiore 43, 50144 Florence, Italy

e-mail: srinaldi@irf.it

M. Lotti Margotti

Department of Information Technology and Statistical Analysis, Rinaldi Fontani Institute, Viale Belfiore 43,

50144 Florence, Italy

C. Ventura

Cardiovascular Department, S. Orsola-Malpighi Hospital,

University of Bologna, Via Masserenti 9, Bologna, Italy fibroblasts in vitro. The purpose of the present work was to verify whether TO-RGN may also be effective in counteracting the expression of the senescence marker beta-galactosidase and of senescence-associated gene expression patterning, engaged during prolonged culture of human adipose-derived stem cells (hADSCs). Following TO-RGN exposure, we observed a significant downregulation in beta-galactosidase staining and in the expression of the senescence mediator genes p16INK4, ARF, p53, and $\mathrm{p} 21^{\mathrm{CIP} 1}$. Moreover, differently formed untreated cells, TO-RGN-exposed hADSCs maintained their typical fibroblast-like morphology and exhibited a multilineage potential even at late passages, as shown by the remarkable preservation of commitment to osteogenic, adipogenic, chondrogenic, and vasculogenic fates, both at morphologic and gene expression levels. In conclusion, our study highlights a positive effect of TO-RGN in counteracting degenerative senescence processes in vitro.

Keywords Ageing $\cdot$ Anti-aging $\cdot$ Adipose-derived stem cells $\cdot$ Geroconversion $\cdot$ REAC

\section{Introduction}

Ageing is a complex process characterized by loss of tissue homeostasis and a progressive and widespread decline in physical performance and cognitive functions of the whole organism. Tissue integrity is 
physiologically maintained by resident stem cells, which are able to replace damaged or lost cells. Recent advances in stem cell research have proposed an intriguing hypothesis concerning ageing: exhaustion of stem cells may be a primary cause of ageing (Sharpless and DePinho 2007; Sahin and Depinho 2010). Adult stem cells can be found in tissues throughout the human body, including bone marrow and fat. These cells although pluripotent, contrary to embryonic stem cells, have a differentiation capability limited to the retention of tissue homeostasis, by replacing damaged or dying cells throughout the human life span (Bryder et al. 2006; Morrison and Kimble 2006). They exhibit specific physiological and biochemical properties. First of all, mesenchymal stem cells (MSCs) can differentiate into distinctive endstage cell types, required to form many mesenchymal tissues, including bone, cartilage, muscle, bone marrow stroma, tendons/ligaments, fat, dermis, and other connective tissues. Moreover, MSCs participate to the injury response by a so-called "homing capacity," through which they can localize into the damaged tissue and secrete a wide range of bioactive molecules with "trophic activity" (Wright et al. 2001). However, the regenerative capability of MSCs is subjected to a series of biochemical changes that occurs during ageing, and deeply affect their self-renewal potential. It seems that the expression of specific mediators of senescence, may act through tumor suppressing and growth arrest mechanisms, playing a very important role in aging. Among these, the cyclin-dependent kinase inhibitors, p16INK4a and ARF, significantly accumulates with normal aging in rodents and humans in cells of a variety of tissues (Alcorta et al. 1996; Rheinwald et al. 2002; Randle et al. 2001; Chkhotua et al. 2003; Melk et al. 2004; Nielsen et al. 1999; Zindy et al. 1997). The activation of p16INK4a and ARF induces p53 pathways, including the expression of the cyclin-dependent kinase inhibitors p $21^{\mathrm{CIP} 1}$, leading to cell cycle arrest and regenerative defects (Bringold and Serrano 2000).

Moreover, during ageing, cells undergo senescenceassociated changes which include cellular widening, higher lysosome biogenesis, and expression of a betagalactosidase that has a $\mathrm{pH}$ optimum of 6 (senescenceassociated $\beta$-galactosidase or SA- $\beta$-Gal). It is now generally accepted that stem cells, which undergo accelerated cellular senescence, can contribute to age-related diseases (Vijg and Campisi 2008). We have previously shown that a treatment, named tissue optimizationregenerative (TO-RGN), of radio-electric asymmetric conveyer (REAC) technology (Rinaldi and Fontani 2000, 2001), significantly influenced the differentiation capability of mouse embryonic stem cells (Maioli et al. 2011), as well as pluripotency and plasticity of human skin-derived fibroblasts (Maioli et al. 2012a). In the present study, we investigated whether TO-RGN may be able to counteract the expression of SA- $\beta$-Gal and modulate the transcription of a number of senescence mediator genes, recruited throughout prolonged culturing of human, adipose-derived stem cells (hADSCs).

\section{Material and methods}

\section{Ethics statement}

According to the policy approved by the local ethical committee of the University of Bologna (title of approved project: "Assessment of mesenchymal stem cells in human adipose tissue," code number 013/2010/O/Tess, date of approval from the ethical committee: 16 February 2010), all tissue samples were obtained after informed consent. All participants, according to the consent procedure approved by the ethical committee, provided their written consent specifically dedicated to the harvesting of their abdominal fat (50-100 $\mathrm{mL}$ of lipoaspirate).

Radio-electric asymmetric conveyer technology for therapeutic use

REAC is an innovative patented technology (WO2002004069) (Rinaldi and Fontani 2000, 2001) for bio-stimulation and/or bio-enhancement techniques that induces weak radio-electric currents in the tissues, to induce a cell reprogramming activity (Maioli et al. 2012a). The model used in this study (B.E.N.E Bio enhancer-Neuro enhancer, ASMED, Florence, Italy) is specific for regenerative treatments. Recently, using TO-RGN treatment protocol, the REAC technology has demonstrated the chance to drive stem cell pluripotency and differentiation (Maioli et al. 2011), and a cell reprogramming activity (Maioli et al. 2012a).

The physical underpinnings of REAC technology are the following: upon interaction of two oscillators, namely two electromagnetic fields, a resultant 
oscillatory pattern may be generated, in actual fact a resultant current and magnetic field. Exploitation of the REAC technology implies that among the interacting oscillators, one is represented by the oscillating electromagnetic field generated by cells or by the entire organism and the other by a weaker electromagnetic field produced by the REAC apparatus itself. Upon the establishment of such a dual system, a resultant electromagnetic field is generated that induces the cells or the organism to respond in an autologous fashion with self-generated radio-electric microcurrents, likely ensuing from an array of cellular ionic fluxes. By the aid of REAC technology, these autologous radio-electric currents can be asymmetrically focused with a conveyer probe to produce a therapeutic effect on a given selected area of the entire organism or elicit transcriptional and signaling events that drive reprogramming and differentiating decisions in isolated (stem) cell cultures. The unique features of the REAC technology thus provide a complete customization and non-invasiveness of treatments, in the absence of side effects, due to the nature of the treatment itself. On the whole, these achievements pave the way to novel perspectives at the level of both basic science and clinical settings that are currently approached according to specific validated protocols.

REAC tissue optimization: regenerative treatment (TO-RGN)

The REAC TO-RGN consists of a sequence of radio frequency burst of $250 \mathrm{~ms}$ with an off interval of $2.5 \mathrm{~s}$. The REAC apparatus, was placed into a $\mathrm{CO}_{2}$ incubator, was set at a frequency of $2.4 \mathrm{GHz}$, and its conveyer electrodes were immersed into the culture medium of hADSCs. REAC radiated power is about $2 \mathrm{~mW}$, electric field $E=0.4 \mathrm{~V} / \mathrm{m}$, Magnetic field $1 \mathrm{~mA} / \mathrm{m}$, specific absorption rate (SAR) $0.128 \mu \mathrm{W} / \mathrm{g}$; the density of radio-electric current flowing in the culture medium during the REAC single radio frequency burst is $J=30 \mu \mathrm{A} / \mathrm{cm}^{2}$.

Isolation and culture of hADSCs

Human subcutaneous adipose tissue samples were obtained from lipoaspiration/liposuction procedures by 50 -year-old female donors $(n=14)$. Their mean BMI was 25.47 and their mean age was 49.57. After washing, lipoaspirates were digested with $0.2 \%$ collagenase A type I solution (Sigma-Aldrich), under gentle agitation for $45 \mathrm{~min}$ at $37^{\circ} \mathrm{C}$, and centrifuged at $2,000 \times g$ for $10 \mathrm{~min}$ to separate the stromal vascular fraction from adipocytes. If necessary, the hADSC fraction was treated with red blood cell lysis buffer for $5 \mathrm{~min}$ at $37{ }^{\circ} \mathrm{C}$, and then centrifuged again. The supernatant was discarded, and the cell pellet was resuspended and seeded in culture flasks in DMEMlow glucose (Lonza) supplemented with $20 \%$ heat inactivated FBS, $1 \%$ penicillin-streptomycin, $2 \mathrm{mM}$ L-glutamine, and incubated at $37{ }^{\circ} \mathrm{C}$ in a humidified atmosphere with $5 \% \mathrm{CO}_{2}$. When the cultures were near confluence, the cells were detached by treatment with trypsin and seeded in six-well tissue culture plates $\left(3 \times 10^{3}\right.$ cells $\left./ \mathrm{cm}^{2}\right)$ at the appropriate passages. The REAC apparatus, was placed into a $\mathrm{CO}_{2}$ incubator, was set at $2.4 \mathrm{GHz}$, and its conveyer electrodes were immersed for 4,8 , or $12 \mathrm{~h}$ into the culture medium of hADSCs at passages 5, 10, 15, 20, 25, and 30 . The widths and lengths of at least ten individual controls and TO-RGN-treated hADSCs at different passages were recorded using an Olympus IX71 fluorescence-inverted microscope at $100 \times$ magnification oil immersion. Images were analyzed with the software "ANALYSIS," and these data were averaged to produce a single average measurement of cell length and width.

Characterization of hADSCs by flow cytometry analysis

ADSCs obtained from adipose tissues were harvested by treatment with $0.08 \%$ trypsin-EDTA and incubated with $1 \mu \mathrm{g} / 10^{6}$ cells FITC-conjugated antibodies for $40 \mathrm{~min}$ at $4{ }^{\circ} \mathrm{C}$ in the dark. The antibodies used were: SH2, SH3, SH4, anti-CD166, anti-CD14, anti-CD34, anti-CD44, and anti-CD45. After washing, cells were analyzed on a flow cytometer (FACSCalibur, Becton Dickinson, San Jose, CA, USA) by collecting 10,000 events and the data analyzed using the Cell Quest Software (Becton Dickinson). hADSCs were positively stained with $\mathrm{SH} 2$, which identifies an epitope of endoglin (CD105), were recognized by the SH3 and SH4 antibodies, which identify epitopes on cultureexpanded stromal cells and bind CD73, a molecule involved in B cell activation. hADSCs were also positive for CD29, the beta-subunit of an integrin family behaving as the major receptor for extracellular matrix molecules, CD166, an hMSC marker not found in 
hematopoietic precursors, and were uniformly positive for the CD44 hyaluronate receptor. Conversely, antigen profiles were negative for the hematopoietic markers CD14 and CD34 and the leukocyte common antigen CD45.

Senescence associated $\beta$-galactosidase staining

SA- $\beta$-Gal staining was performed using a "Senescenceassociated $\beta$-Galactosidase Staining Kit" (Cell Signalling). Briefly, hADSCs cultured at passages 5, $10,15,20,25$, and 30 were exposed for $12 \mathrm{~h}$ in the absence or presence of REAC in six-well plates $\left(3 \times 10^{3}\right.$ cells per well). Subsequently, cells were fixed with fixative solution and then processed according to the manufacturer's instructions. All the experiments were repeated three times, and one of the representative results was shown. The cells were then photographed under an inverted microscope at $100 \times$ magnification for qualitative detection of SA- $\beta$-Gal activity. The number of positive (blue) and negative cells was counted in five random fields under the microscope (at $200 \times$ magnification and bright field illumination), and the percentage of SA- $\beta$-Gal-positive cells was calculated as the number of positive cells divided by the total number of counted cells.
Assessment of cell viability

hADSCs cultured at passages 5, 10, 15, 20, 25, and 30 were exposed for $12 \mathrm{~h}$ in the absence or presence of REAC in six-well plates $\left(6 \times 10^{3}\right.$ cells per well). Cell viability was determined by the trypan blue dye exclusion test (Life Technologies). Both attached and floating cells were harvested and counted by using countess automated cell counter.

Adipogenesis, osteogenesis, and vasculogenesis in culture

To test cell capability to differentiate toward mesenchymal phenotypes, hADSCs at passages 5 and 30, exposed or not to REAC for $12 \mathrm{~h}$, were committed toward adipogenic, osteogenic, and vascular phenotypes. To induce adipogenic differentiation, $10 \times$ $10^{3}$ cells $/ \mathrm{cm}^{2}$ were cultured in an adipogenesis induction medium (Millipore) composed by DMEM-low glucose, supplemented with $10 \%$ FBS, $0.5 \mathrm{mM}$ isobutyl-methylxanthine, $200 \mu \mathrm{M}$ indomethacin, $1 \mu \mathrm{M}$ dexamethasone, and $10 \mu \mathrm{g} / \mathrm{mL}$ insulin in a $24-$ well microplate, replacing the medium every 2-3 days. At day 7 and 10 of differentiation, total RNA was extracted and the expression of the two adipogenic

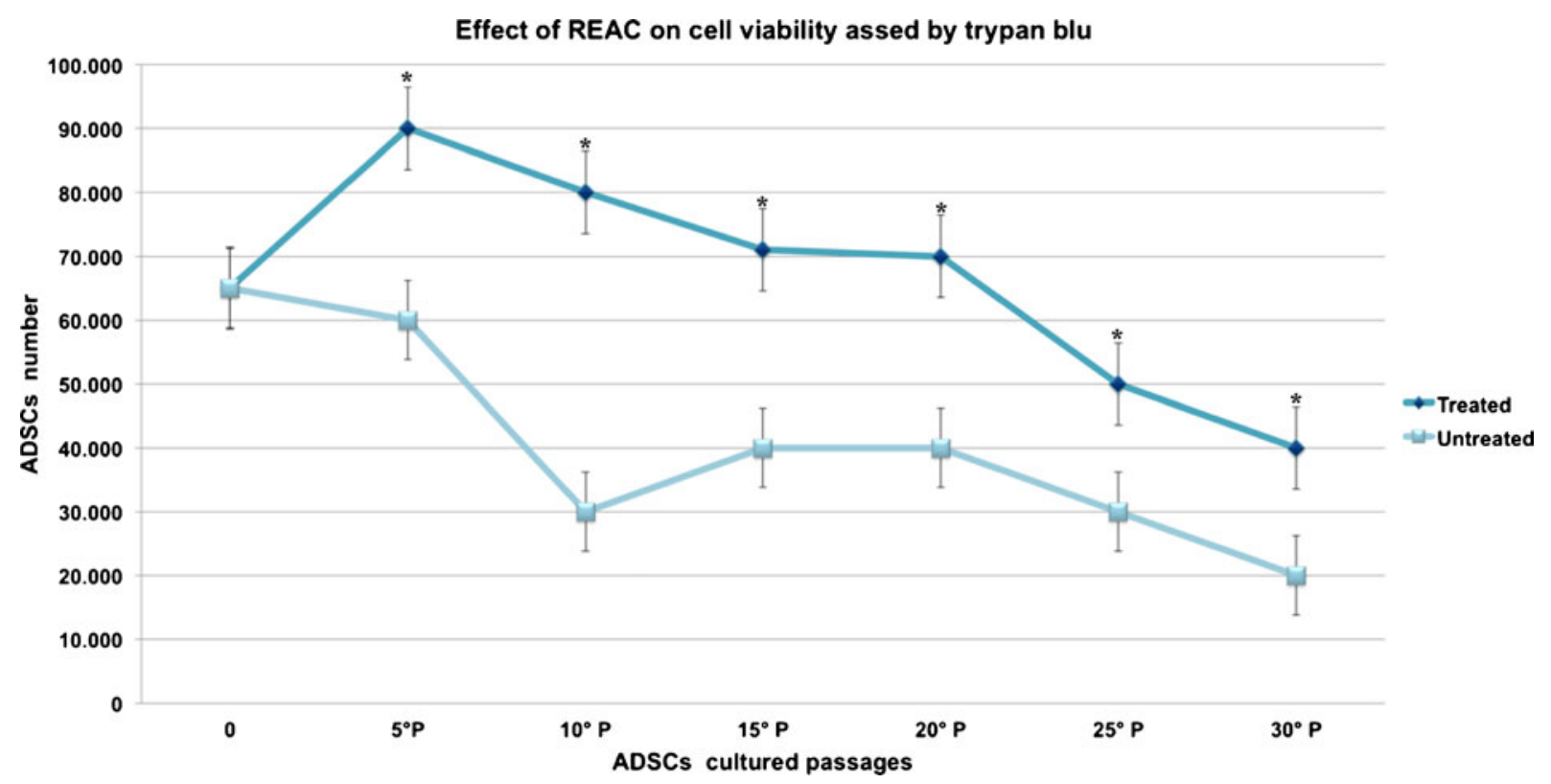

Fig. 1 TO-RGN exposure enhances hADSC viability. After plating $\left(6 \times 10^{3}\right.$ cells/well), cells were left untreated or treated with TO-RGN for $12 \mathrm{~h}$ and counted to estimate cell growth. The number of vital cells assed by trypan blue dye exclusion was significantly higher in REAC-exposed samples than in untreated controls. (Asterisk) significantly different from untreated cells (mean $\pm \mathrm{SD}, n=4)(P<0.05)$ 
markers, adipocyte Protein $2(\mathrm{aP} 2)$ and peroxisome proliferator-activated receptor $\gamma$ (PPAR $\gamma)$, was evaluated by real-time PCR. After 2-3 weeks of culture, the cells were fixed in $10 \%$ formalin and stained with fresh oil red-O solution. To induce osteogenic differentiation, $10 \times 10^{3}$ cells $/ \mathrm{cm}^{2}$ were plated in a 24 -well microplate in DMEM-low glucose supplemented with $10 \%$ FBS, $10 \mathrm{mM} \beta$-glycerophosphate, $0.2 \mathrm{mM}$ ascorbic acid, and $10 \mathrm{nM}$ dexamethasone (Mesenchymal Stem Cell Osteogenesis Kit, Millipore), and cultured for 3-4 weeks, replacing the medium every $2-3$ days. To demonstrate osteogenic differentiation, the cultures were fixed and stained with Alizarin Red solution, and total RNA was extracted to evaluate specific osteogenic differentiation related genes, as Runt-related transcription factor 2 (RUNX-2) and bone sialoprotein (BSP). Concerning angiogenesis, as previously shown the expression of vasculogenic genes, including vascular endothelial growth factor (VEGF), and von Willebrand factor (vWF) genes can be remarkably enhanced following the exposure of hADSCs to a mixture of natural molecules including hyaluronan $(\mathrm{H})$, butyric $(\mathrm{B})$, and retinoic acids

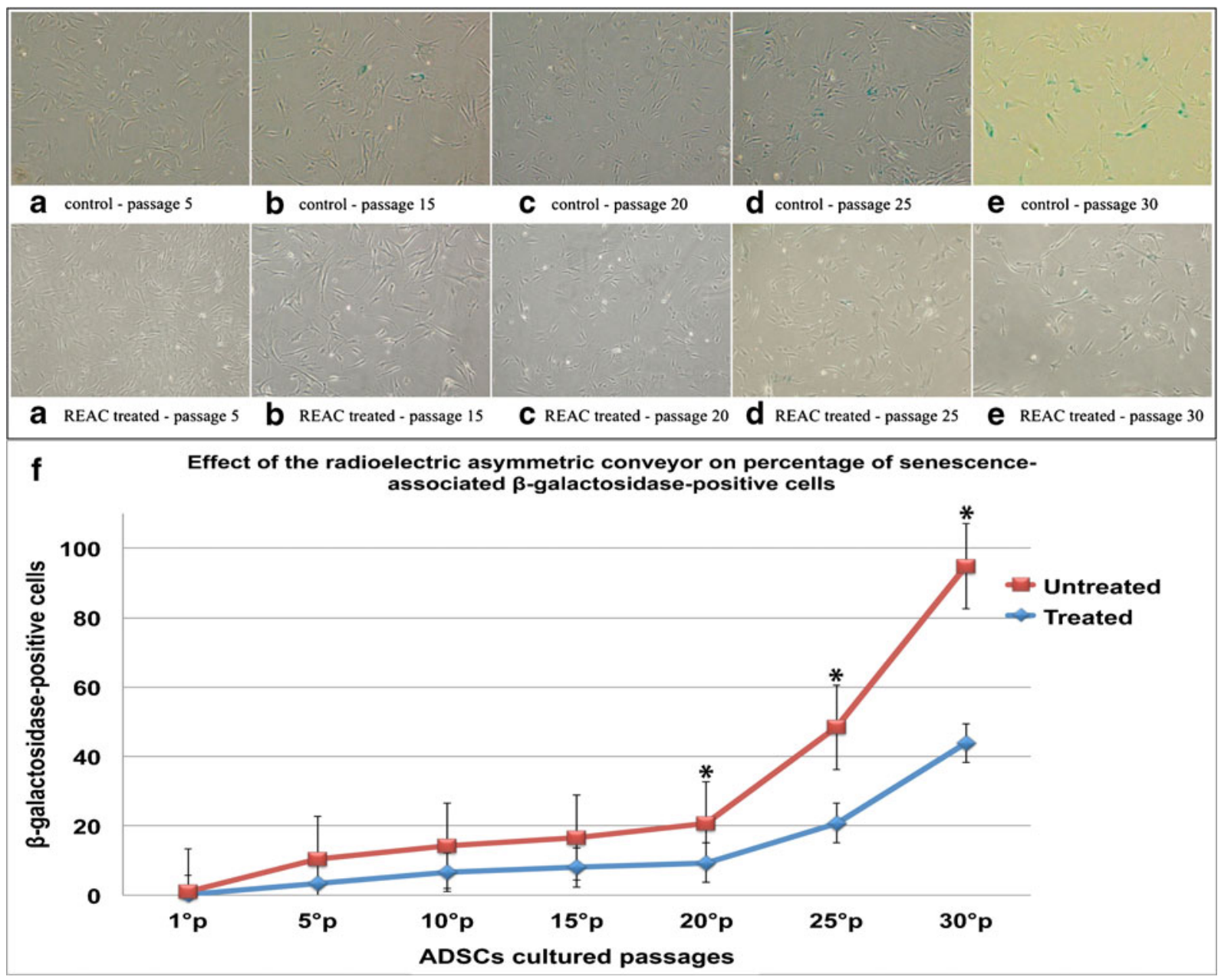

Fig. 2 REAC TO-RGN counteracts senescence-associated $\beta$ galactosidase activity. hADSCs at passages 5 (panels $A$ ), 15 (panels B), 20 (panels C), 25 (panels D), and 30 (panels E) were plated in six-well plates $\left(3 \times 10^{3}\right.$ cells per well). After overnight culture for attachment, cells were cultured in the absence or presence of REAC for $12 \mathrm{~h}$. Then, hADSCs were processed for SA- $\beta$-Gal assessment and photographed under a microscope at $100 \times$ magnification. SA- $\beta-$ Gal activity was measured after culturing for $12 \mathrm{~h}$ with (blue line) or without TO-RGN (red line) treatment (panel F). The number of positive (blue staining) and negative cells was counted in five random fields under the microscope (at 200 $\times$ magnification and bright field illumination), and the percentage of SA- $\beta$-Gal-positive cells was calculated as the number of positive cells divided by total number of counted cells. (Asterik) significantly different from the untreated cells (mean $\pm \mathrm{SD}, n=3)(P<0.05)$ 

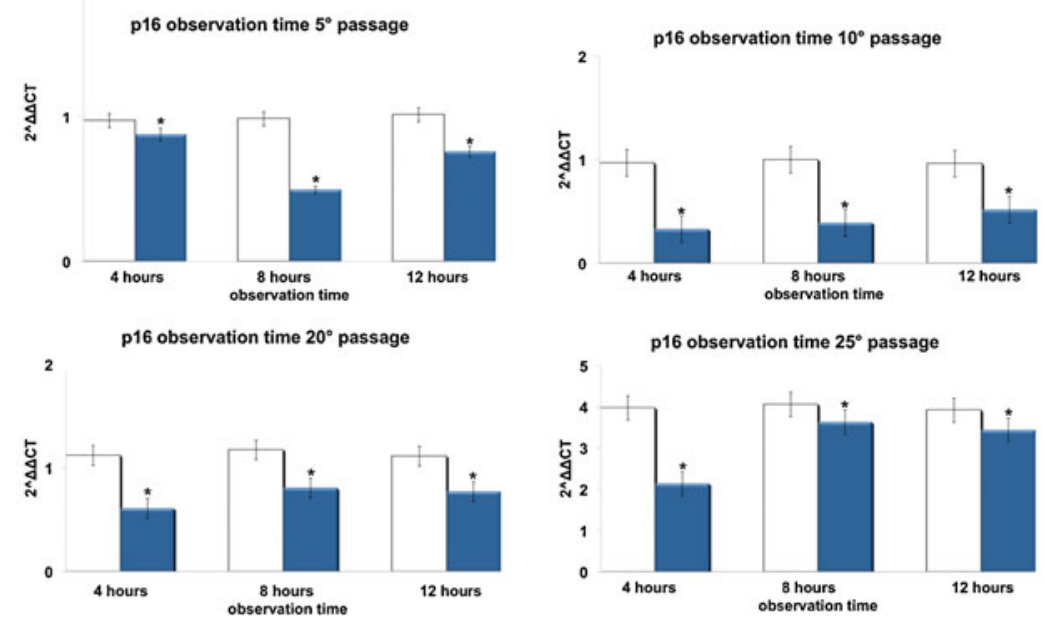
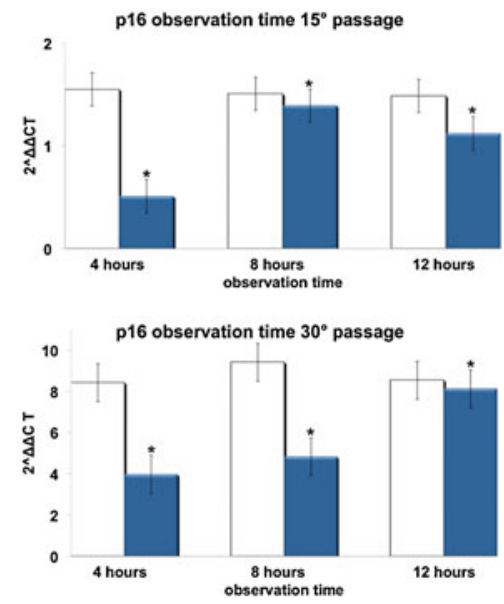

Fig. 3 Effect of REAC TO-RGN on p16INK4a gene expression. hADSCs at passages $5,10,15,20,25$, and 30 , reaching $80 \%$ confluence, were exposed for 4,8 , or $12 \mathrm{~h}$ in the absence or presence of REAC. The amount of p16INK4a mRNA from control (white bars) and TO-RGN treated (blue bars) cells was normalized to HPRT1 and was plotted as fold change relative to the mRNA expression at passage 5 (time 0 ), defined as 1 . (Asterisk) significantly different from the untreated cells (mean \pm S.E.; $n=6)(P<0.05)$
(R) (Bianchi et al. 2012; Cavallari et al. 2012). Here, we use a 24-72-h exposure to a mixture containing $\mathrm{H}$ $(2 \mathrm{mg} / \mathrm{mL}), \mathrm{B}(5 \mathrm{mM})$, and $\mathrm{R}(1 \mu \mathrm{M})$ to induce the expression of the vasculogenic gene VEGF, and the vascular marker vWF factor. Analysis of capillary-like tube formation was performed using Cultrex ${ }^{\circledR}$ Basement Membrane Extract (BME, Thema). Capillary-like structures were observed after $12-24 \mathrm{~h}$ at regular time intervals, and photographed using an inverted optical microscope equipped with a digital sight camera (Nikon).

Gene expression

Total RNA was isolated from hADSCs exposed or not to TO-RGN for 4,8 , or $12 \mathrm{~h}$, using Trizol reagent according to the manufacturer's instruction (Life
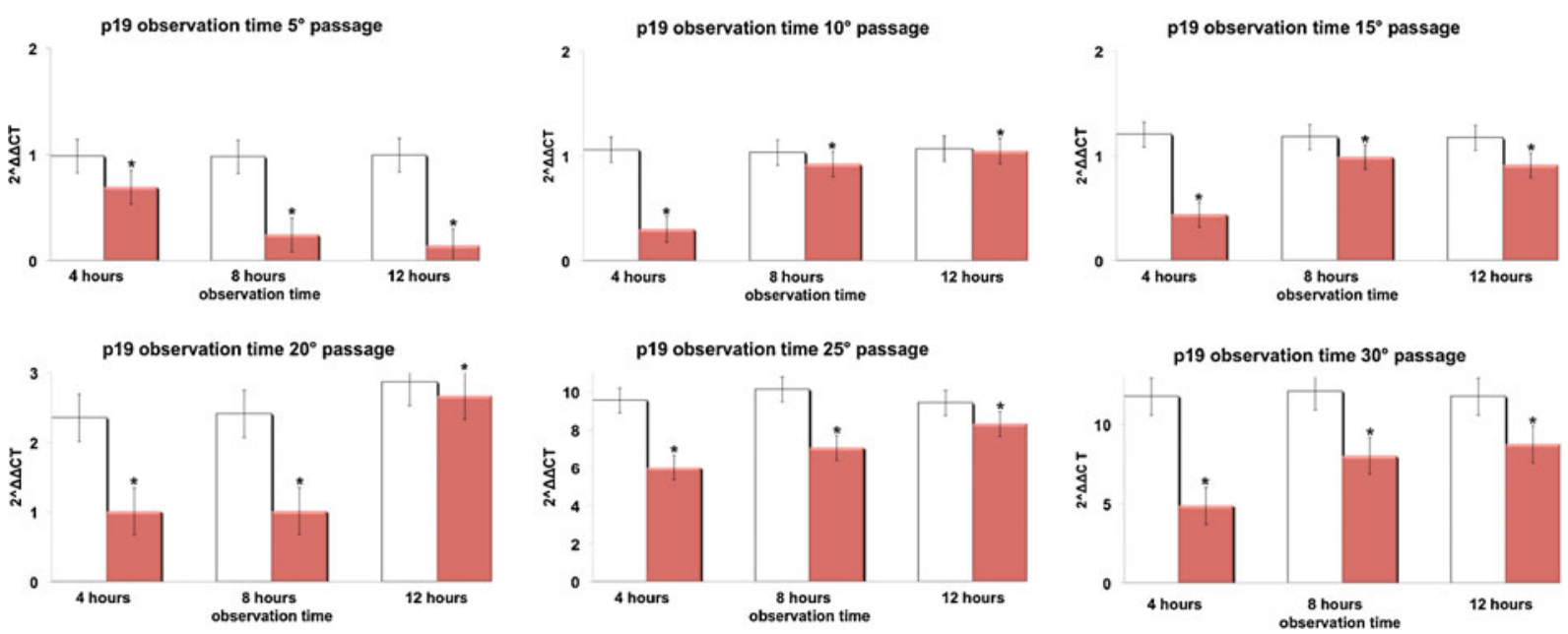

Fig. 4 Effect of REAC TO-RGN on ARF gene expression. hADSCs at passages $5,10,15,20,25$, and 30 , reaching $80 \%$ confluence, were exposed for 4,8 , or $12 \mathrm{~h}$ in the absence or presence of REAC. The amount of ARF mRNA from control (white bars) and TO-RGN- treated (red bars) cells was normalized to HPRT1 and was plotted as fold change relative to the mRNA expression at passage 5 (time 0 ), defined as 1. (Asterisk) significantly different from the untreated cells (mean \pm S.E.; $n=6)(P<0.05)$ 

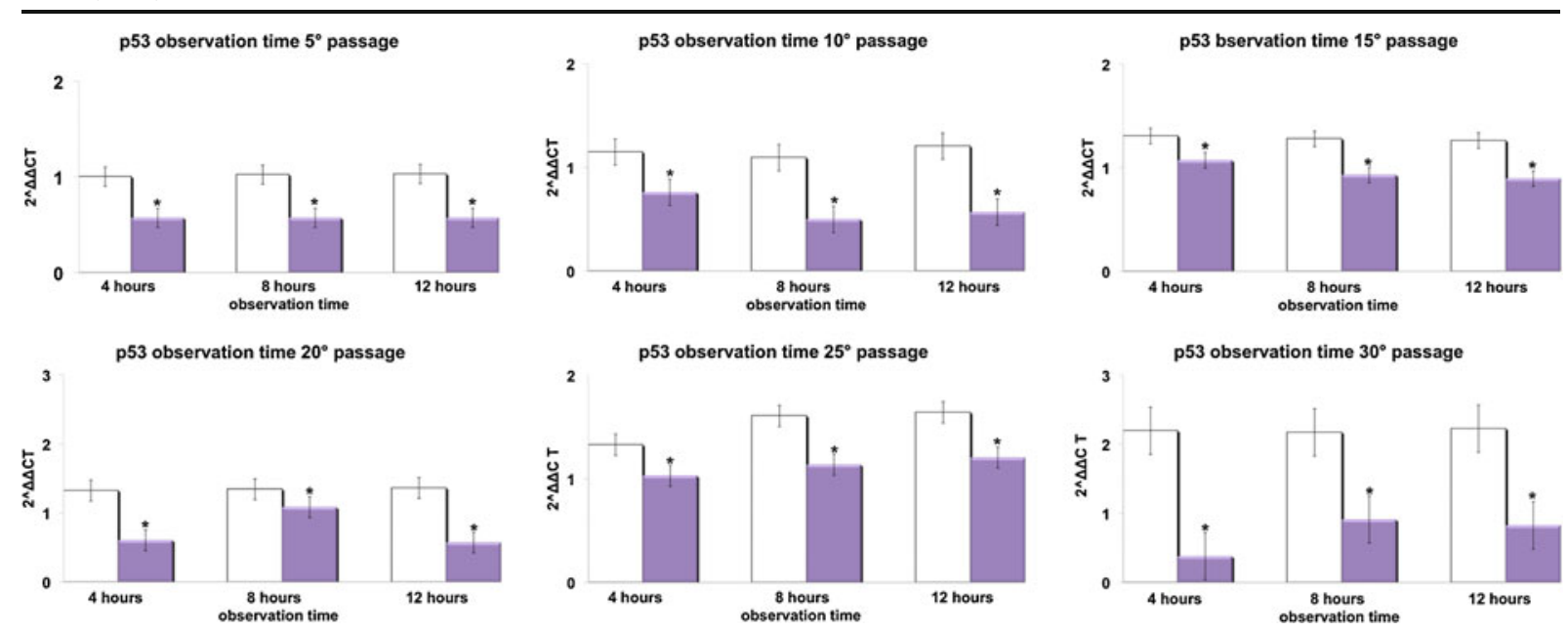

Fig. 5 Effect of REAC TO-RGN on p53 gene expression. hADSCs at passages $5,10,15,20,25$, and 30 , reaching $80 \%$ confluence, were exposed for 4,8 , or $12 \mathrm{~h}$ in the absence or presence of REAC. The amount of p53 mRNA from control (white bars) and TO-RGN- treated (purple bars) cells was normalized to HPRT1 and was plotted as fold change relative to the mRNA expression at passage 5 (time 0 ), defined as 1. (Asterisk) significantly different from the untreated cells (mean \pm S.E.; $n=6)(P<0.05)$
Technologies). Total RNA was also isolated from control and REAC-treated hADSCs (time of exposure $12 \mathrm{~h}$ ) at passages $5^{\circ}$ and $30^{\circ}$ committed toward adipogenic (at days 7 and 10 of culture), osteogenic (at day 7 of culture) and vascular (at day 7 of culture) phenotypes. Total RNA was dissolved in RNAase-free water, and for RT-PCR, cDNA was synthesized in a $50-\mu \mathrm{L}$ reaction volume with $1 \mu \mathrm{g}$ of total RNA and MuMLV reverse transcriptase (RT) according to the manufacturer's instruction (Invitrogen). Quantitative real-time PCR was performed using an iCycler Thermal Cycler (Bio-Rad). Two microliters of cDNA were amplified in $50-\mu \mathrm{L}$ reactions using Platinum Supermix UDG (Invitrogen), $200 \mathrm{nM}$ of each primer, $10 \mathrm{nM}$ fluorescein (BioRad), and Sybr Green. After an initial denaturation step at $94{ }^{\circ} \mathrm{C}$ for $10 \mathrm{~min}$, temperature cycling was initiated.
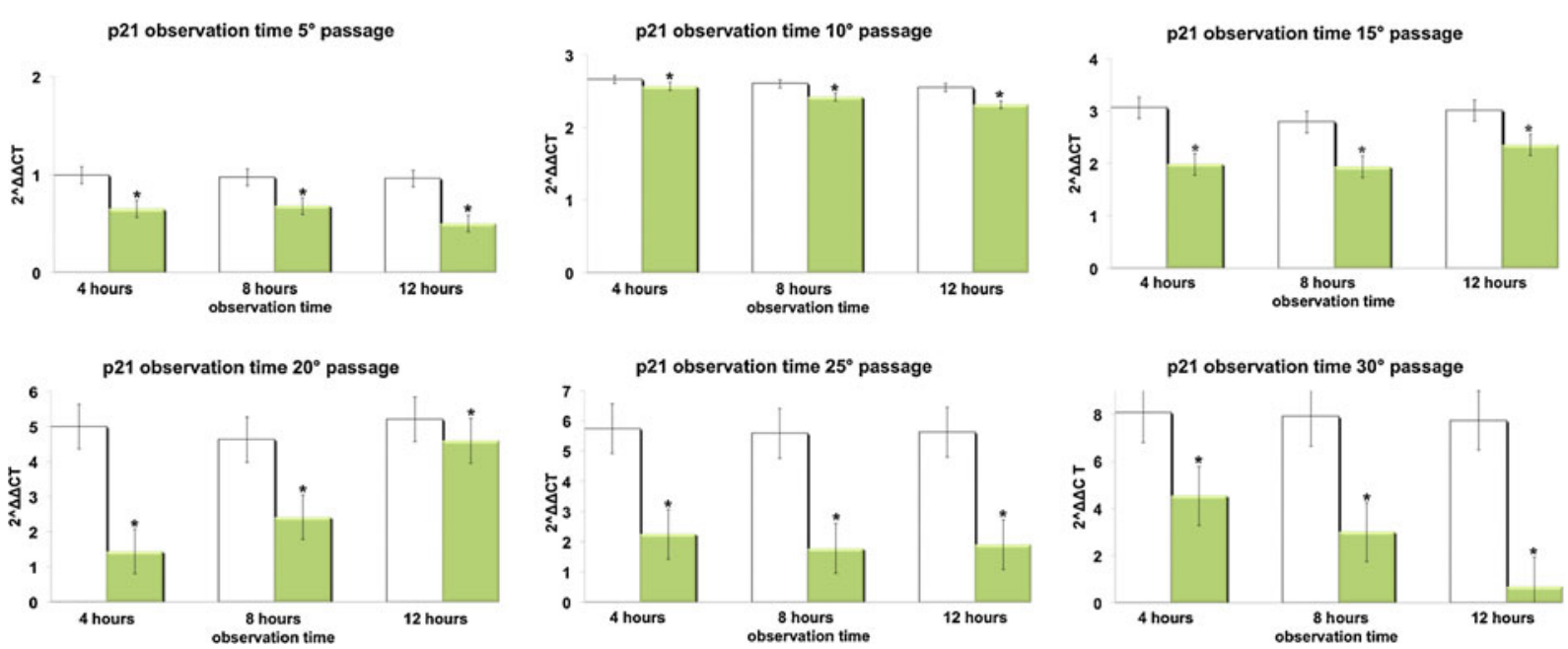

Fig. 6 Effect of REAC TO-RGN on p21 gene expression. hADSCs at passages $5,10,15,20,25$, and 30 , reaching $80 \%$ confluence, were exposed for 4,8 , or $12 \mathrm{~h}$ in the absence or presence of REAC. The amount of p21 mRNA from control (white bars) and TO-RGN- treated (green bars) cells was normalized to HPRT1 and was plotted as fold change relative to the mRNA expression at passage 5 (time 0 ), defined as 1 . (Asterisk) significantly different from the untreated cells (mean \pm S.E.; $n=6)(P<0.05)$ 


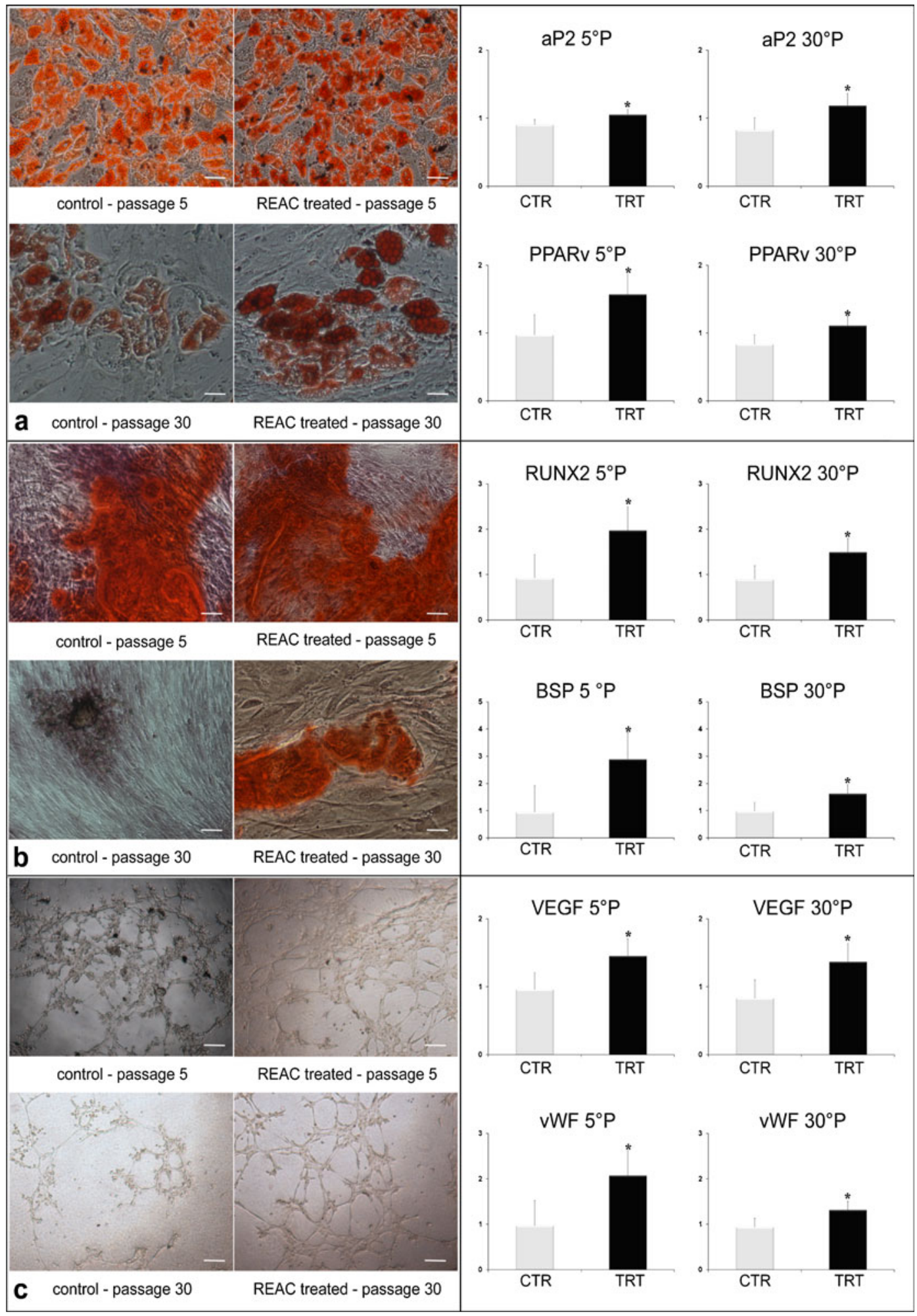


4Fig. 7 Effect of REAC on multi-lineage differentiation and gene expression patterning in hADSCs cultured at different passages in the absence or presence of REAC. At passages 5, or 30 , hADSCs were treated for $12 \mathrm{~h}$ in the absence or presence of REAC, and processed as described under "Material and methods" for: a adipogenic differentiation, revealed by Oil Red-O staining for neutral lipids (100× magnification), and by the gene expression of aP2 and PPAR $\gamma ; \mathbf{b}$ osteogenic differentiation, evidenced by the formation of mineralized matrix, as shown by Alizarin Red staining (100× magnification), and by the gene expression of BSP and RUNX2. c Vasculogenic differentiation was assessed by capillary tube-like formation in semisolid medium after $24 \mathrm{~h}$ of treatment in the absence or presence of REAC (100×, original magnification), and by the gene expression analysis of VEGF and VWF. (White bars) untreated controls; (black bars) REAC-treated cells. Immunohistochemistry is representative of four separate experiments. For gene expression analyses, total RNA was extracted after 7 days in culture. (Asterisk) Significantly different from untreated control cells (mean \pm S.E.; $n=6$ )

Each cycle consisted of $94{ }^{\circ} \mathrm{C}$ for $15 \mathrm{~s}, 55-59{ }^{\circ} \mathrm{C}$ for $30 \mathrm{~s}$, and $60{ }^{\circ} \mathrm{C}$ for $30 \mathrm{~s}$, the fluorescence being read at the end of this step. To evaluate the quality of product of real-time PCR assays, melting curve analysis was performed after each assay. Relative expression was determined using the "delta-CT method" with hypoxanthine phosphoribosyltransferase 1 (HPRTl) as a reference gene. The mRNA levels of control and TO-RGN exposed hADSCs were expressed as fold of change $(2-\Delta \Delta \mathrm{Ct})$, relative to the mRNA levels of the enzyme evaluated in hADSCs at passage 5 when cells reached $80 \%$ confluence before starting TO-RGN treatment (time 0).

Specific primers for p16, p19, p21, p53, and HPRT1 used in this study were from Invitrogen and previously described (Maioli et al. 2011; Bea et al. 2001; Isenmann et al. 2007; Vandesompele et al. 2002; Maioli et al. 2012b). Specific primers used for adipogenic commitment were: aP2 forward 5'AGACATTCTACGGGCAGCAC-3' and reverse 5'TCATTTTCCCACTCCAGCCC-3', and PPAR $\gamma$ forward 5'-GCAAACCCCTATTCCATGCTG-3' and reverse GCAGGCTCCACTTTGATTGC.

Specific primers for osteogenic commitment, as core binding factor alpha 1 (CBFA1/RUNX-2), and BSP, were previously described (Polini et al. 2011).

Specific primers for angiogenesis as VEGF were previously described (Ventura et al. 2007) while primers for the vascular marker vWF were: forward 5'-GCCTGTGGGAGCAGTGCCAG-3' and reverse 5'-GGGCGTACTCCAGGAGGGCA-3'.
Data analysis

The statistical analysis of the data was performed by using the Statistical Package for Social Science, version 13. For this study, nonparametric statistical tests were used: Friedman and Wilcoxon-signed rank test. The first was used to detect differences in treatments across multiple test attempts; the second was used to evaluate, in the same group, the differences (delta CT) between the data collected over a period of observation related to the treated and nontreated cells. Test, and all results $P<0.05$ have been considered statistically significant.

\section{Results}

TO-RGN treatment remarkably influenced cell viability, as shown by its ability to significantly enhance the number of vital cells as compared to untreated controls (Fig. 1). Figure 2 (panels A-F) represents SA- $\beta-G a l$ staining in hADSCs cultured in the absence or presence of TO-RGN throughout an observation period of 90 days. It is evident that the number of SA- $\beta$-Galstained cells (blue) was already significantly reduced at passage 5 in TO-RGN-treated hADSCs. This behavior became more evident with the passage of time in culture, with a progressive increment in the difference of positively SA- $\beta$-Gal-stained cells between REAC exposed and unexposed cells (Fig. 2, panels $\mathrm{A}-\mathrm{F}$ ). Moreover, in the last passages not only the number of SA- $\beta$-Gal positive cells, but also the intensity of the SA- $\beta$-Gal staining was remarkably reduced following TO-RGN exposure. Separate analysis of cellular morphology revealed that unlike control cells, which developed an ailing morphology in the last passages, TORGN-exposed cells still exhibited their classical fibroblast-like morphology, even at passages 25 and 30. In particular, length to width ratio was higher in REACtreated cells, ranging between $8.078 \pm 0.6$ and 5.043 \pm 0.55 (mean \pm SD from ten separate REAC-exposed cell cultures at passages 25 and 30, respectively), as compared to untreated cells, ranging between $5.025 \pm 0.35$ and $3.993 \pm 0.33$ (mean \pm SD from ten separate untreated control cell cultures at passages 25 and 30, respectively).

Figures 3, 4, 5, and 6 show respectively the gene expression of p16INK4, ARF, p53 and p21 in hADSCs at passages 5, 10, 15, 20, 25, and 30 treated, or not, with TO-RGN for 4,8 , or $12 \mathrm{~h}$. The expression 
of p16, ARF p53, and p21 increased throughout the investigated culturing passages (Figs. 3, 4, 5, and 6) in control hADSCs, while it was significantly less detectable in TO-RGN-exposed cells. Moreover, this effect of TO-RGN was particularly evident at passages 25 and 30. hADSCs at passages 5 and 30 treated with TORGN exhibited also a higher differentiation capability toward adipogenic, osteogenic, and vasculogenic lineages, as compared to control cells (Fig. 7, panels a-c). Adipogenic differentiation showed multiple adipocytic multivacuolar cells, the size increasing with the time of induction (Fig. 7, panels a). Moreover, hADSCs at passages 30 exposed to TO-RGN also expressed higher levels of the adipogenic-associated genes, aP2 and PPAR $\gamma$, as compared to control cells (Fig. 7, panels a). Osteogenic differentiation was revealed as early as the first week of induction by morphological changes and, at the end of the induction period, by the formation of mineralized matrix and calcium deposits as demonstrated by Alizarin Red staining (Fig. 7, panels b). Gene expression analysis of osteogenic-associated genes, RUNX2 and BSP revealed higher expression levels of both factors in TO-RGN-treated hADSCs, as compared to control cells (Fig. 7, panels b). Vasculogenic differentiation was assessed in control or TO-RGN-treated hADSCs cultured for $24 \mathrm{~h}$ in semisolid medium, at passages 5 and 30 (Fig. 7, panels c). The TO-RGN treatment increased both the number of capillary-like tubes and their branching assembly, as compared with unexposed controls (Fig. 7, panels c). The higher vasculogenic differentiation capability of TO-RGNtreated hADSCs was also inferred by their enhanced expression of the vasculogenic gene VEGF and of the vascular specific gene $v W F$, with respect to untreated cells (Fig. 7, panels c).

\section{Discussion}

It has been demonstrated that the regenerative capability of stem cells isolated from elder patients is lower as compared to younger subjects (Lapasset et al. 2011). This age-related alteration, together with a reduced self-renewal potential of adult stem cells, can also be observed during long-term culture in vitro (Chambers and Goodell 2007). Therefore, identifying a strategy that could revert the molecular cues controlling stem cell senescence in vitro may represent an important progress for future cell therapy development. Indeed, advances in the perspective of a regenerative medicine were recently obtained by reversing the age-altered physiology of the stem cells by the aid of viral vectors (Sawada et al. 2006). Alternatively, (stem) cell rejuvenation has been shown after culturing in a hypoxic environment (Barros et al. 2013; Leontieva et al. 2012; Malladi et al. 2007), a condition influencing cell proliferation and fate (Malladi et al. 2007; Mohyeldin et al. 2010), although hypoxia was also found to induce apoptosis in bone marrow-derived hMSCs (Zhu et al. 2006).

In the present work, we analyzed the effect of TORGN treatment on hADSC senescence in vitro, and demonstrated that this physical treatment, without the aid of viral vectors, was able to counteract biochemical and morphological changes occurring in stem cells during aging. Such a conclusion could be inferred from a number of interrelated observations, including (1) the effectiveness of TO-RGN to decrease both the number of SA- $\beta$-Gal-positive cells and their staining intensity, (2) the ability of TO-RGN-treated cells to retain the typical fibroblast-like morphology of hADSCs, with respect to the enlarged shape acquired by unexposed cells through prolonged culturing, (3) the remarkable preservation of the multilineage differentiating potential observed in TO-RGN exposed hADSCs that even at late passages retained their adipogenic, osteogenic, and vasculogenic potential, as compared with the multipotency decline found in aged, unexposed cells.

It is now evident that senescence is also regulated by specific mediator genes, accumulating during the cell life span, including p16INK4, ARF, p53, and p21CIP1. In particular, p16INK4 and ARF inhibit the activity of cyclin-dependent kinase 4 and 6, essential for the G1 progression through the cell cycle, while $\mathrm{p} 53$ regulates the expression of $\mathrm{p} 21 \mathrm{CIP} 1$, which inhibits cyclin-dependent kinase2, a regulator of the $\mathrm{S}$ phase progression (Zou et al. 2002).

Our observation that TO-RGN exposure was also effective in counteracting the progressive upregulation of these genes occurring throughout multiple passages in culture supports future clinical application of REAC technology as a potential tool for blunting age-related degenerative diseases.

Further studies are in progress to investigate whether the TO-RGN treatment may also interact with the multifaceted signal patterning through which hypoxia determines the cell state and inhibits geroconversion (Leontieva et al. 2012). 
Acknowledgments The authors thank Lucia Aravagli, M.D. and Stefania Bini, M.D. Department of Neuro Psycho Physio Pathology, Rinaldi Fontani Institute, Florence, Italy, for their helpful discussions.

Open Access This article is distributed under the terms of the Creative Commons Attribution License which permits any use, distribution, and reproduction in any medium, provided the original author(s) and the source are credited.

\section{References}

Alcorta DA, Xiong Y, Phelps D, Hannon G, Beach D, Barrett JC (1996) Involvement of the cyclin-dependent kinase inhibitor p16 (INK4a) in replicative senescence of normal human fibroblasts. Proc Natl Acad Sci U S A 93(24):13742-13747

Barros SD, Dehez S, Arnaud E, Barreau C, Cazavet A, Perez G, Galinier A, Casteilla L, Planat-Benard V (2013) Agingrelated decrease of human ASC angiogenic potential is reversed by hypoxia preconditioning through ROS production. Mol Ther 21(2):399-408. doi:10.1038/mt.2012.213

Bea S, Tort F, Pinyol M, Puig X, Hernandez L, Hernandez S, Fernandez PL, van Lohuizen M, Colomer D, Campo E (2001) BMI-1 gene amplification and overexpression in hematological malignancies occur mainly in mantle cell lymphomas. Cancer Res 61(6):2409-2412

Bianchi F, Maioli M, Leonardi E, Olivi E, Pasquinelli G, Valente S, Mendez AJ, Ricordi C, Raffaini M, Tremolada C, Ventura C (2012) A new non-enzymatic method and device to obtain a fat tissue derivative highly enriched in pericyte-like elements by mild mechanical forces from human lipoaspirates. Cell Transplant. doi:10.3727/096368912X657855

Bringold F, Serrano M (2000) Tumor suppressors and oncogenes in cellular senescence. Exp Gerontol 35(3):317-329

Bryder D, Rossi DJ, Weissman IL (2006) Hematopoietic stem cells: the paradigmatic tissue-specific stem cell. Am J Pathol 169(2):338-346. doi:10.2353/ajpath.2006.060312

Cavallari G, Olivi E, Bianchi F, Neri F, Foroni L, Valente S, La Manna G, Nardo B, Stefoni S, Ventura C (2012) Mesenchymal stem cells and islet cotransplantation in diabetic rats: improved islet graft revascularization and function by human adipose tissue-derived stem cells preconditioned with natural molecules. Cell Transplant 21(12):2771-2781. doi:10.3727/096368912X637046

Chambers SM, Goodell MA (2007) Hematopoietic stem cell aging: wrinkles in stem cell potential. Stem Cell Rev 3(3):201-211

Chkhotua AB, Gabusi E, Altimari A, D'Errico A, Yakubovich M, Vienken J, Stefoni S, Chieco P, Yussim A, Grigioni WF (2003) Increased expression of p16(INK4a) and p27(Kip1) cyclin-dependent kinase inhibitor genes in aging human kidney and chronic allograft nephropathy. Am J Kidney Dis 41(6): 1303-1313

Isenmann S, Cakouros D, Zannettino A, Shi S, Gronthos S (2007) hTERT transcription is repressed by Cbfal in human mesenchymal stem cell populations. J Bone Miner Res 22(6):897-906. doi:10.1359/jbmr.070308

Lapasset L, Milhavet O, Prieur A, Besnard E, Babled A, AitHamou N, Leschik J, Pellestor F, Ramirez JM, De Vos J,
Lehmann S, Lemaitre JM (2011) Rejuvenating senescent and centenarian human cells by reprogramming through the pluripotent state. Genes Dev 25(21):2248-2253. doi:10.1101/ gad.173922.111

Leontieva OV, Natarajan V, Demidenko ZN, Burdelya LG, Gudkov AV, Blagosklonny MV (2012) Hypoxia suppresses conversion from proliferative arrest to cellular senescence. Proc Natl Acad Sci U S A 109(33):13314-13318. doi:10.1073/pnas.1205690109

Maioli M, Rinaldi S, Santaniello S, Castagna A, Pigliaru G, Gualini S, Fontani V, Ventura C (2011) Radio frequency energy loop primes cardiac, neuronal, and skeletal muscle differentiation in mouse embryonic stem cells: a new tool for improving tissue regeneration. Cell Transplant. doi:10.3727/096368911X600966

Maioli M, Rinaldi S, Santaniello S, Castagna A, Pigliaru G, Gualini S, Cavallini C, Fontani V, Ventura C (2012a) Radio electric conveyed fields directly reprogram human dermalskin fibroblasts towards cardiac-, neuronal-, and skeletal muscle-like lineages. Cell Transplant. doi:10.3727/ 096368912 X657297

Maioli M, Rinaldi S, Santaniello S, Castagna A, Pigliaru G, Gualini S, Fontani V, Ventura C (2012b) Radiofrequency energy loop primes cardiac, neuronal, and skeletal muscle differentiation in mouse embryonic stem cells: a new tool for improving tissue regeneration. Cell Transplant 21(6):1225-1233. doi:10.3727/096368911X600966

Malladi P, Xu Y, Chiou M, Giaccia AJ, Longaker MT (2007) Hypoxia inducible factor-1alpha deficiency affects chondrogenesis of adipose-derived adult stromal cells. Tissue Eng 13(6):1159-1171. doi:10.1089/ten.2006.0265

Melk A, Schmidt BM, Takeuchi O, Sawitzki B, Rayner DC, Halloran PF (2004) Expression of p16INK4a and other cell cycle regulator and senescence associated genes in aging human kidney. Kidney Int 65(2):510-520. doi:10.1111/ j.1523-1755.2004.00438.x

Mohyeldin A, Garzon-Muvdi T, Quinones-Hinojosa A (2010) Oxygen in stem cell biology: a critical component of the stem cell niche. Cell Stem Cell 7(2):150-161. doi:10.1016/ j.stem.2010.07.007

Morrison SJ, Kimble J (2006) Asymmetric and symmetric stemcell divisions in development and cancer. Nature 441(7097):1068-1074. doi:10.1038/nature04956

Nielsen GP, Stemmer-Rachamimov AO, Shaw J, Roy JE, Koh J, Louis DN (1999) Immunohistochemical survey of p16INK4A expression in normal human adult and infant tissues. Lab Invest 79(9):1137-1143

Polini A, Pisignano D, Parodi M, Quarto R, Scaglione S (2011) Osteoinduction of human mesenchymal stem cells by bioactive composite scaffolds without supplemental osteogenic growth factors. PLoS One 6(10):e26211. doi:10.1371/ journal.pone.0026211

Randle DH, Zindy F, Sherr CJ, Roussel MF (2001) Differential effects of p19(Arf) and p16(Ink4a) loss on senescence of murine bone marrow-derived preB cells and macrophages. Proc Natl Acad Sci U S A 98(17):9654-9659. doi:10.1073/pnas.171217498

Rheinwald JG, Hahn WC, Ramsey MR, Wu JY, Guo Z, Tsao H, De Luca M, Catricala C, O'Toole KM (2002) A two-stage, p16(INK4A)- and p53-dependent keratinocyte senescence mechanism that limits replicative potential independent of telomere status. Mol Cell Biol 22(14):5157-5172 
Rinaldi S, Fontani, V. (2000) Radioelectric asymmetric conveyer for therapeutic use. EP1301241 (B1), October 11, 2006

Rinaldi S, Fontani, V. (2001) Radioelectric asymmetric conveyer for therapeutic use. USA Patent 7,333,859, February 19,2008

Sahin E, Depinho RA (2010) Linking functional decline of telomeres, mitochondria and stem cells during ageing. Nature 464(7288):520-528. doi:10.1038/nature08982

Sawada R, Ito T, Tsuchiya T (2006) Changes in expression of genes related to cell proliferation in human mesenchymal stem cells during in vitro culture in comparison with cancer cells. J Artif Organs 9(3):179-184. doi:10.1007/s10047006-0338-z

Sharpless NE, DePinho RA (2007) How stem cells age and why this makes us grow old. Nat Rev Mol Cell Biol 8(9):703713. doi:10.1038/nrm2241

Vandesompele J, De Preter K, Pattyn F, Poppe B, Van Roy N, De Paepe A, Speleman F (2002) Accurate normalization of real-time quantitative RT-PCR data by geometric averaging of multiple internal control genes. Genome Biol 3(7):RESEARCH0034

Ventura C, Cantoni S, Bianchi F, Lionetti V, Cavallini C, Scarlata I, Foroni L, Maioli M, Bonsi L, Alviano F, Fossati V, Bagnara GP, Pasquinelli G, Recchia FA, Perbellini A (2007) Hyaluronan mixed esters of butyric and retinoic acid drive cardiac and endothelial fate in term placenta human mesenchymal stem cells and enhance cardiac repair in infarcted rat hearts. J Biol Chem 282(19):14243-14252. doi:10.1074/jbc.M609350200

Vijg J, Campisi J (2008) Puzzles, promises and a cure for ageing. Nature 454(7208):1065-1071. doi:10.1038/ nature 07216

Wright DE, Wagers AJ, Gulati AP, Johnson FL, Weissman IL (2001) Physiological migration of hematopoietic stem and progenitor cells. Science 294(5548):1933-1936. doi:10.1126/science.1064081

Zhu W, Chen J, Cong X, Hu S, Chen X (2006) Hypoxia and serum deprivation-induced apoptosis in mesenchymal stem cells. Stem Cells 24(2):416-425. doi:10.1634/ stemcells.2005-0121

Zindy F, Quelle DE, Roussel MF, Sherr CJ (1997) Expression of the p16INK4a tumor suppressor versus other INK4 family members during mouse development and aging. Oncogene 15(2):203-211. doi:10.1038/sj.onc. 1201178

Zou X, Ray D, Aziyu A, Christov K, Boiko AD, Gudkov AV, Kiyokawa H (2002) Cdk4 disruption renders primary mouse cells resistant to oncogenic transformation, leading to Arf/p53-independent senescence. Genes Dev 16(22):2923-2934. doi:10.1101/gad.1033002 